\title{
On the Effect of ECAP Processing Temperature on the Microstructure, Texture Evolution and Mechanical Properties of Commercial Pure Copper
}

\section{A.I. Alateyah ${ }^{\star}, \mathbb{1}$}

In this study, the severe plastic deformation (SPD) behavior of commercial-grade pure copper processed using equal channel angular pressing (ECAP) was investigated. The copper rods were processed for up to 4 passes, both at room temperature and $200{ }^{\circ} \mathrm{C}$. The microstructure and texture evolution were studied using a field emission scanning electron microscope (FESEM) equipped with an electron back scattered (EBSD) detector. The effect of ECAP processing on the tensile properties, micro-hardness, and impact toughness was studied. After 1 pass, the average grain size of the rods was determined to be 2.694 and $3.9066 \mu \mathrm{m}$ at room temperature and $200{ }^{\circ} \mathrm{C}$, respectively. In addition, after 4 passes through ECAP, the strength of the ECAPed samples increased to $381 \mathrm{MPa}$, and $330 \mathrm{MPa}$ at room temperature and $200^{\circ} \mathrm{C}$, respectively; and the Vickers' micro-hardness at the peripheral areas increased to 158, and 126, respectively. In the other hand, the experimental findings revealed that the number of ECAP passes has insignificant effect on the impact energy.

\section{Introduction}

In the last decade, a large demand of the industries for a material with high level of strength and conductivity is widely undergoing. Several types of metals which includes, silver, copper, gold and aluminum are largely utilized due to their level of electrical conductivity. In term of cost comparison, the aluminum and copper are the most reasonable price with the advantage of this conductivity. However, these materials have lower electrical conductivity with compared to other metals due to two reasons. The first one, the impurities that enlarge the electron scattering by thermal vibrations of the crystal lattice. The second one, the attendance of structural imperfections which contain grain boundaries and dislocations [1-3]. The Ability of balancing this issue is via obtaining of the both pure materials with improvement of mechanical strength. The enhancement of various metals strength such as copper can be reached by heat treatment and the addition of other alloying elements. However, this technique can lower the ductility and electric conductivity

Mechanical Engineering Department, College of Engineering, Unizah, Qassim University, 51911, Kingdom of Saudi Arabia

*Corresponding author:

E-mail: A.Alateyah@qu.edu.sa

DOI: 10.5185/amlett.2021.091661
[4]. The other successful way is by improving the structure to obtain ultrafine-grained (UFG) and a large grain boundary area $[\mathbf{5 , 6}]$. These outcomes can be reached by undertaken severe plastic deformation method (SDP) [613].

Severe plastic deformation technique has been used widely nowadays due to their influence on the microstructure behavior. The production of ultrafinegrained microstructures and the deformation of metallic and alloy materials can be achieved by this process.

The most applicable processes of the (SDP) is equalchannel angular pressing (ECAP) due to their highly effective of fabricating different types of ultrafine-grained materials [14-20], producing nano-crystalline bulk materials [21], improving both mechanical and physical properties [5], achieving the homogenously deformation of bulk material $[\mathbf{2 2 , 2 3}]$ and the dealing with the mechanics of metal flow and the microstructural evolution [20]. Furthermore, the ductility of material can be enhanced by utilizing ECAP, since the enhancement of a duplex microstructure shaped by nanometric grains sized coupled with micrometric or UFG without sacrificing the martials strength [24].

The ECAP method can utilized various sample's shape such as rectangular, square, or circular. By unlimited number of passes throughout the die, the severe shear deformation of microstructure can be obtained during this way without dramatic changes in the dimensions. As a 


\section{Advanced Materials Letters https://aml.iaamonline.org}

result, the material can be pressed many times to attain a high total strain [17]. The die of ECAP includes two channels with the same cross-section intersecting at an angle (between $90^{\circ}$ and $157^{\circ}$ ). At $90^{\circ}$, the strain is approximately about 1 each pass. The high friction and high boundaries angle can be reached by large number of passes which lead on enhancing the mechanical properties dramatically $[\mathbf{7 , 1 7 , 1 9 , 2 5 - 2 7 ]}$. Nowadays, recent modification had been introduced on the ECAP process to facilitate conducting high passes of ECAP for various materials such as rotary-die (RD) ECAP [28-30].

This study intends to analyze the mechanical traits, texture along with micro structural development of $\mathrm{Cu}$ that is free from impurities and has been subjected to maximum 4 passes through ECAP die at $120^{\circ}$. To define the microscopic bodies, high-resolution backscatter diffraction (EBSD) was used that helped to numerically evaluate the characteristics of microstructures; for instance, disorientation of grain boundary, quality and dimensions in the ECAPed samples subjected to processing. The stiffness of contour maps is used to determine the diversity in the mechanical behavior.
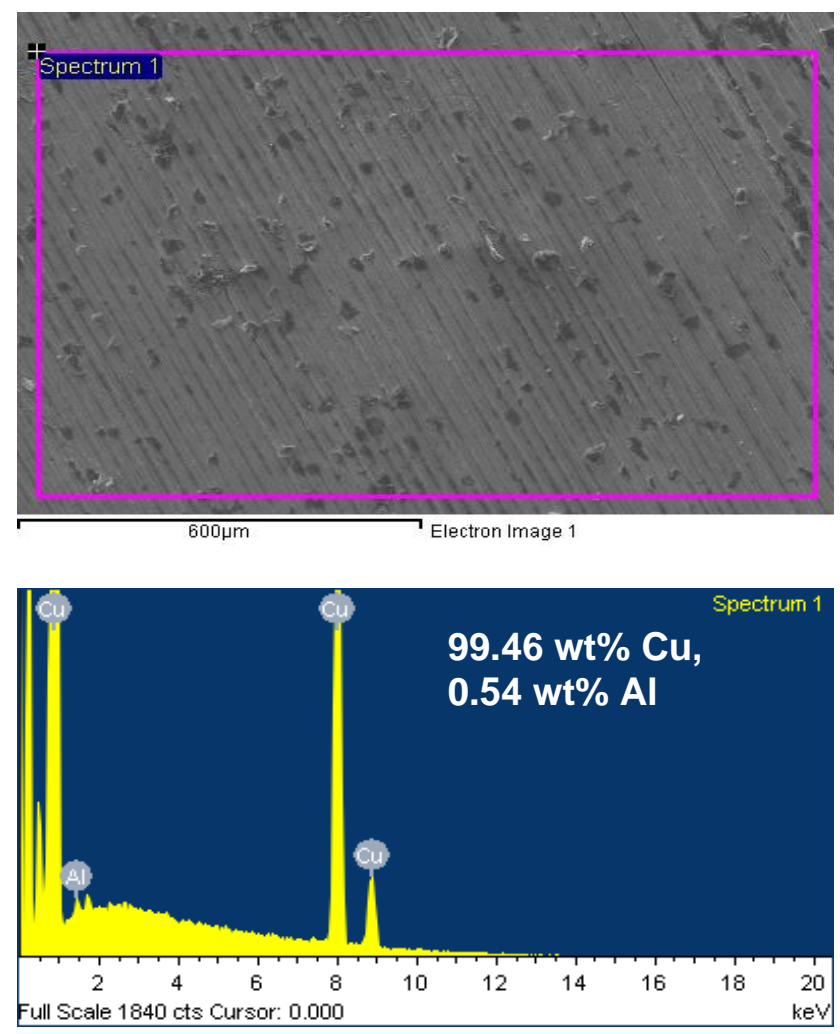

Fig. 1. A scanning electron microscopy (a), and EDX (b) micrographs for the commercial pure $\mathrm{Cu}$

\section{Materials and experimental procedure}

$\mathrm{Cu}$ bars attributed with $99.46 \%$ purity $(99.46 \mathrm{wt} \% \mathrm{Cu}$, $0.54 \mathrm{wt} \% \mathrm{Al}$ ) and $20 \mathrm{~mm}$ diameter when formed into rolled billets were taken for this experimentation. Scanning electron microscopy (SEM) as well as energy dispersive spectroscopy X-ray (EDS) were used to examine the chemical configuration of $\mathrm{Cu}$ billets when they were received. SEM is shown in Fig. 1(a) while EDS in Fig. 1(b). Accordingly, Fig. 1(b) illustrates that commercial pure $\mathrm{Cu}$ contains $\mathrm{Cu}$ only and also contain trivial amount of impurities such as chlorine. It was found that the asannealed (AA) $\mathrm{Cu}$ sample microstructure showed inconsistent shape and size. The average size of grains was $4.5 \mu \mathrm{m}$ and the smaller grains were located all around the coarse ones which were in the center. Fig. 2 depicts that the size of the grains had a range between 0.7 and $27 \mu \mathrm{m}$.

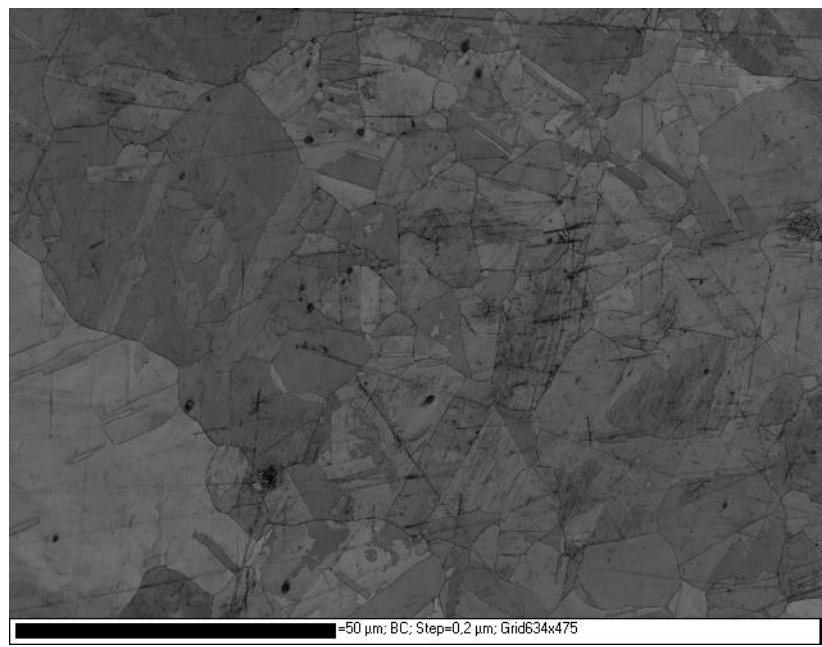

Fig. 2. SEM micrograph for the AA Cu rod.

Highly accurate cutting equipment was employed for the purpose of cutting and processing while $20 \mathrm{~mm}$ wide and $70 \mathrm{~mm}$ long ECAP samples were shaped with the help of a lathe. Each $\mathrm{Cu}$ sample is subjected to annealing at $500{ }^{\circ} \mathrm{C}$ for an hour before the processing, and then furnace is cooled to achieve a consistent microstructure. The processing of $\mathrm{Cu}$ bars was done by 1 , and 4 ECAP passes via $\mathrm{BC}$ route. The entire process was carried out at room temperature and $0.15 \mathrm{~mm} / \mathrm{s}$ ram speed was maintained. During this process, at the end of each pass, the sample was turned around at $90^{\circ}$ angle longitudinally without changing its direction.

In order to reduce resistance between ECAPed samples and die's interior wall, a graphite-based lubricant is applied prior to the start of each pass. The impact of processing temperature on the samples, one more ECAPed sample was taken and subjected to processing for 1 and 4 passes via the $\mathrm{Bc}$ route keeping the temperature at $200 \mathrm{C}^{\mathrm{o}}$. Fig. 3 depicts a schematic for the ECAP processing die. The process involved the insertion of two parts of route at an internal route angle equal to $\varphi=120^{\circ}$. Besides this, there was an outer corner angle equal to $\psi=10^{\circ}$. The billets before and after ECAP process were sectioned along the center of the longitudinal lines parallel and perpendicular to the direction of eviction followed by the grinding and polishing to give a mirror-like surface. The samples were subjected to Vicker's micro-hardness experiments (Hv) The values were 


\section{Advanced Materials Letters https://aml.iaamonline.org}

measured and noted after developing rectilinear grid pattern where each indentation was $1 \mathrm{~mm}$ apart from the subsequent one. These series of indentations begin at the perimeters of the billets passing through the middle of the section that had been cut close to the top division of the ECAPed samples. This configuration was undertaken for parallel as well as perpendicular divisions towards the extrusion pathway in order to analyze the stiffness disparity all over the longitudinal and perpendicular parts of the ECAPed bars. As far as the longitudinal part is concerned, it was spread over a square area equal to $20 \times 20 \mathrm{~mm}^{2}$ while the perpendicular part was circular in shape and was characterized with a $20 \mathrm{~mm}$ diameter. To test the hardness, $1 \mathrm{~kg}$ load was applied for a period of 15 seconds.

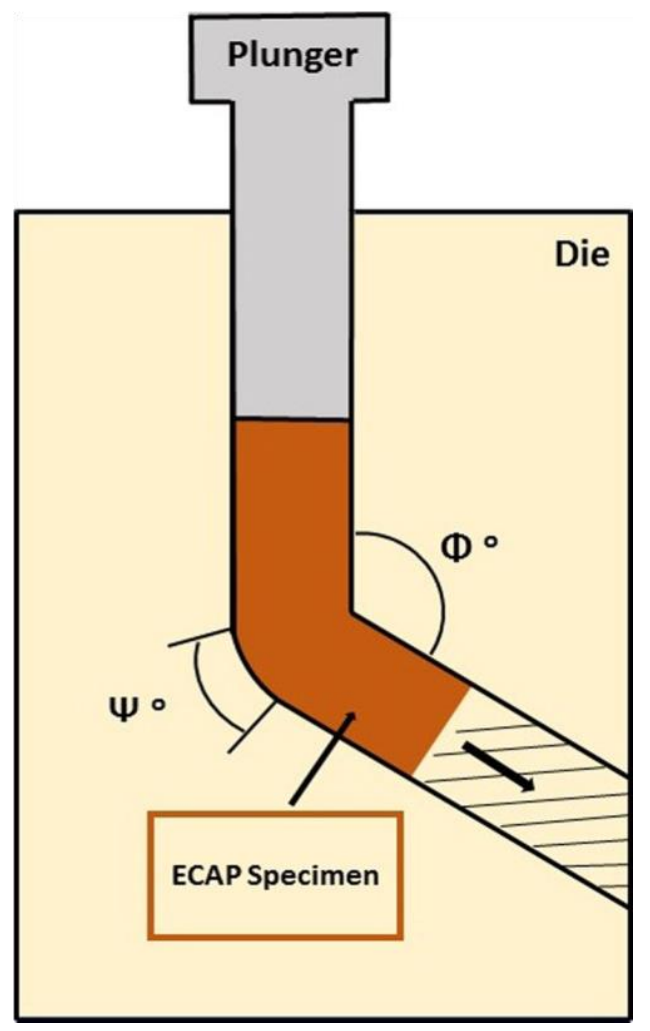

Fig. 3. Schematic of the ECAP die setup showing the de angles $\phi$, and $\Psi$ [31].

At least 5 equally distant indentations were taken, and the average of their outcomes was computed to achieve the outcomes. Moreover, the Hv report and the extent to which they are same were shown by color-coded charts that were developed to show the hardness distribution along the perpendicular and longitudinal sections of the ECAPed samples. Maintaining a reasonable temperature and consistent strain rate of $10^{-3} \mathrm{~s}^{-1}$, the tensile test is carried out on a $100 \mathrm{kN}$ universal testing machine. American Society for Testing of Materials (E8M /ASTM) set some specifications that must be followed to prepare the tensile samples with a gauge length of $24 \mathrm{~mm}$ and a diameter of $6 \mathrm{~mm}$. Each tensile sample was subjected to processing from the middle of ECAPed samples. At each processing stage, two tensile samples had been examined in order to make certain that the display of results is free from errors.

Charpy impact tester were used for determining the impact toughness of the AA and ECAPed $\mathrm{Cu}$ samples. All the $\mathrm{Cu}$ samples were compacted into rectangular

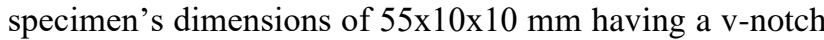
with $2 \mathrm{~mm}$ deep according to ASTM A370. The specimens were placed between the platens of the three-point bending testing machine. 3 samples of each condition were tested.

Micro structural revolution of the rods prior to and after ECAP was defined with the help of field emission scanning electron microscopy (FESEM). The main features of FESEM include energy dispersive spectroscopy (EDS) and electron back scattering diffraction (EBSD) detector namely the NordlysMax2. The process of development of ECAPed bars is explained subsequently: development of bars, mounting of bar samples, grinding and automatic polishing of bars with the help of alumina solution. The last step involves the etching by taking 3 parts of $\mathrm{HCl}$ solution and 1 part of $\mathrm{HNO}_{3}$ by volume. The EDS detector was employed to analyze the distribution of chemical components in pure $\mathrm{Cu}$. Moreover, the experimentation involved the employment of electron back scattered diffraction (EBSD) in order to determine structural evolution as well as crystallographic texture of $\mathrm{Cu}$ rods subjected to processing by passing it through ECAP multiple times.

The sample testing was followed by sample cutting in two equal halves in the direction of ED. This was followed by sample grinding and its automatic polishing with the help of 2500 grit $\mathrm{SiC}$ paper. The usual metallographic procedures were followed during polishing which continued until the emergence of $0.02 \mathrm{~mm}$ colloidal silica suspension. For quantification of EBSD, the tool used was none other than Hitachi SU-70 SEM characterized with operational voltage of $15 \mathrm{kV}$, current of $1.5 \mu \mathrm{A}$ and based on Oxford Instrument's HKL Channel 5 software. Various step sizes including $0.5 \mathrm{~mm}$ (annealed copper), $0.2 \mathrm{~mm}$ (1pass), and $0.05 \mathrm{~mm}$ (4-passes) had been employed. Disorientation less than $3^{\circ}$ is not regarded in the data procedures that are carried out after processing.

\section{Results and discussion}

\section{Microstructure and crystallographic texture}

As depicted in the Fig. 4(a-f), inverse pole figure (IPF) coloring map in the normal direction (ND) of the ECAP extrusion coupled with the miorientation angle distribution. The grain boundary map reveal high angle boundaries (HABs) that have greater than $15^{\circ}$ of disorientation. The mentioned figures also reveal low angle boundaries (LABs) having lesser than $15^{\circ}$ disorientation for both the AA and ECAP pure copper that had been subjected to processing. As shown in the IPF map of the AA sample (Fig. 4(a)), almost all the grains in the microstructure have similar axis in terms of dimension. They encompass annealing twins while the average size of grain is found to be $4.5 \mu \mathrm{m}$. In 


\section{Advanced Materials Letters https://aml.iaamonline.org}

addition, the grain boundary map is given which indicates the complete re-crystallization of microstructure since the map is populated by HABs and depicts a lack of LABs (Fig. 4(b)). The grain size of the microstructure is found to be quite small having an average size of $2.7 \mu \mathrm{m}$ when the first pass of the ECAP is completed. These grains are equiaxed with high density twins as can be seen in Fig. 4(c). Probably; the first grain structure is created by the inert recrystallization, which will occur quickly after ECAP because of heat dissipation [32]. The grain boundary map after the pass explains this phenomenon since this map show minor percentage of LABs (Fig. 4(d)) which can be the result of static re-crystallization process occurring due to heating of highly strain hardened $\mathrm{Cu}$.

It is worth to mentioning here that, $\mathrm{Cu}$ is an fcc material with average amounts of fault energy $(\gamma \mathrm{SFE})$ of about 80 $\mathrm{mJ} / \mathrm{m}^{2}$. During plastic deformation, $\mathrm{Cu}$ dissipates $99 \%$ of the energy in the form of heat while stores $1 \%$ internally. Consequently, static re-crystallization occurs mainly when the temperature of pure copper during re-crystallization is around $180{ }^{\circ} \mathrm{C}[33]$. Due to static re-crystallization, the first pass is fully re-crystallized immediately after the process without any LABs. The resulting microstructure of the first part serves as the initial microstructure for the subsequent ECAP pass. Subsequent to the 4 passes, the microstructure is found to have relatively coarse grains; these grains are characterized with high density of LABs as it can be seen in IPF maps and grain boundary maps in Fig. 4(e-f).

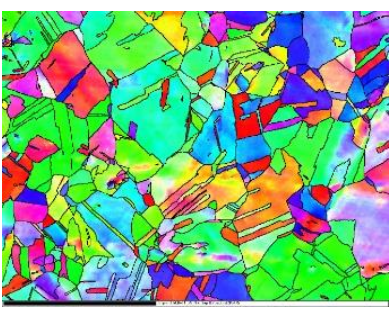

(a)

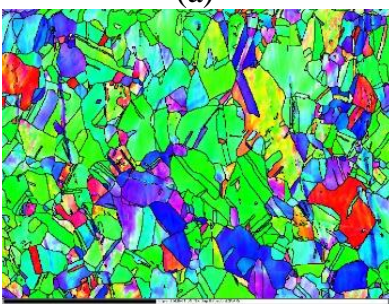

(c)

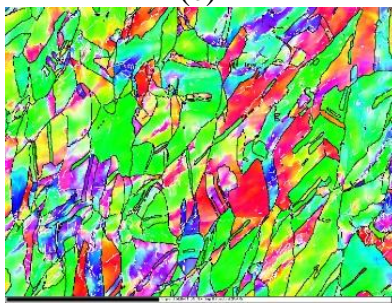

(e)

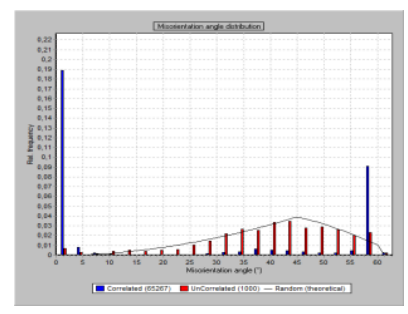

(b)

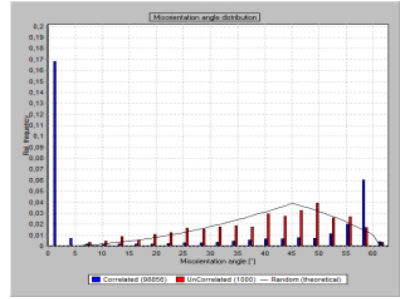

(d)

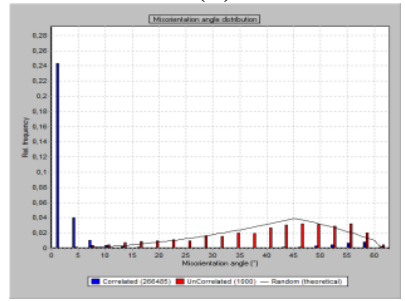

(f)
Fig. 4. IPF coloring map relative to ND and misorientation angle distribution of commercial pure $\mathrm{Cu}$ ECAP processed at room temperature through a, b) AA c, d) 1-P, and e, f) 4-Bc.
After 4 passes, the microstructure depicts almost uniform grain size with an average of approximately 3.6 $\mu \mathrm{m}$. The reason behind the coarse structure of grains at this point is the higher rate of strain hardening during this pass since this pass uses an initial microstructure that had already been processed in the earlier pass. This will help to speed up the process to achieve complete re-crystallization during second ECAP pass. Without affecting grain coarsening, the fourth pass will result in an increase in the number of the substructures. These outcomes show that ECAP process through 1-p has a refining impact while pass 4 resulted in relatively coarser grains with higher substructure density. All these outcomes do not completely agree with the outcomes of other researchers $[\mathbf{3 2}, \mathbf{3 4}]$. The average grain size yielded from the EBSD characterization are shown in Table 1 for the AA, 1-P, and 4-Bc samples processed at room temperature and $200{ }^{\circ} \mathrm{C}$. Fig. 5 shows the misorientation angle relative frequency and grain size variation as a function of the processing condition.

Table 1. The average grain size of the commercial purity $\mathrm{Cu}$ processed through ECAP.

\begin{tabular}{cccc}
\hline Condition & $\begin{array}{c}\text { Average Grain } \\
\text { size }(\boldsymbol{\mu m})\end{array}$ & $\begin{array}{c}\text { Variance } \\
\left(\boldsymbol{\mu \mathbf { m } ^ { 2 } )}\right.\end{array}$ & $\begin{array}{c}\text { Standard } \\
\text { Deviation }(\boldsymbol{\mu m})\end{array}$ \\
\hline AA & 4.5401 & 14.774 & 3.8437 \\
1-P RT & 2.694 & 4.1513 & 2.0375 \\
4-Bc- RT & 3.5675 & 14.969 & 3.869 \\
1-P HT & 3.9066 & 11.427 & 3.3804 \\
4-Bc HT & 2.2966 & 2.3973 & 1.5483 \\
\hline
\end{tabular}

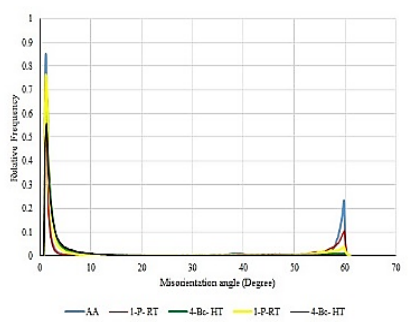

(a)

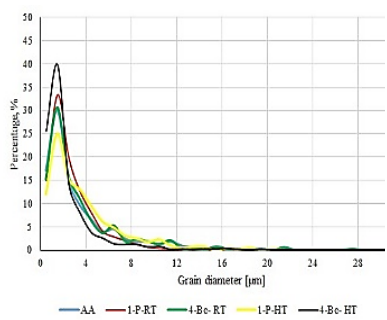

(b)
Fig. 5. (a) The misorientation angle relative frequency and (b) grain size variation as a function of the processing condition.

Higuera-Cobos and Cabrera [32] explored the microstructure of pure $\mathrm{Cu}$ subsequent to ECAP processing. The $\mathrm{Cu}$ sample used in their study was characterized with an initial annealed body with grains of similar axis-length and an average size of $5.5 \mu \mathrm{m}$. They highlighted that the microstructure after first pass contains stretched out grains with refined structure but after 4,8 and 16 passes, the microstructure is saturated and after the fifth pass, there is high diversity in microstructure which includes both large and extremely small grains. Zhu et. al., [34] examined the post-processing microstructure of pure $\mathrm{Cu}$. This $\mathrm{Cu}$ sample was initially attributed with very large grains of $410 \mu \mathrm{m}$. The outcomes depicted a grain refining of approximately $210 \mu \mathrm{m}$ after 4 passes. The development of dislocation cells with the size of $500 \mathrm{~nm}-3 \mu \mathrm{m}$ is observed as the passes are increased to 8 . 


\section{Advanced Materials Letters https://aml.iaamonline.org}

To study the effect of temperature on the micro structural evolution, the process of ECAP was undertaken at the temperature of $200{ }^{\circ} \mathrm{C}$ for the first and fourth passes. Fig. 6 shows the IPF coloring maps related to the ND and misorientation angle distribution for the ECAP processed pure $\mathrm{Cu}$ at $200{ }^{\circ} \mathrm{C}$ for 1 and 4 passes. When the comparison was made between post-processing microstructure of $\mathrm{Cu}$ at room temperature and given $200{ }^{\circ} \mathrm{C}$. The microstructure of the $\mathrm{Cu}$ sample processed through 1-P at $200{ }^{\circ} \mathrm{C}$ depicted an average grain size of $3.9 \mu \mathrm{m}$ (Fig. 6(a)), coarse structure of grains, and reasonable number of LABs $($ Fig. 6(b)). Such microstructures are formed when dynamic re-crystallization occurs during ECAP processing. The subdivision can be noticed along with very heavy LABs in all the observed grains after the 4 passes at $200{ }^{\circ} \mathrm{C}($ Fig. $6(d))$. The standard grain size after $4-\mathrm{Bc}$ at $200{ }^{\circ} \mathrm{C}$ is significantly decreased to be approximately $2.3 \mu \mathrm{m}$ as shown in Fig. 5c. Similar microstructure is also reported by Higuera-Cobos and Cabrera [32] in their study of ECAP processing of pure $\mathrm{Cu}$ for maximum 16 passes at moderate temperature.

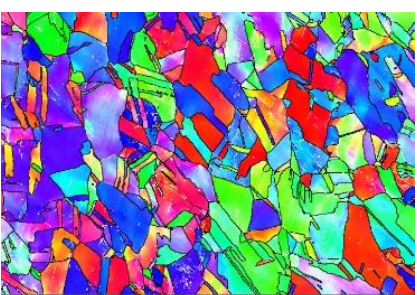

(a)

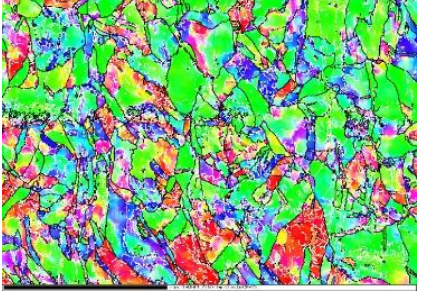

(c)

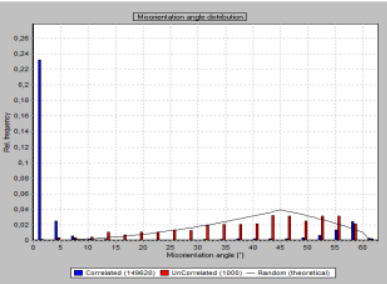

(b)

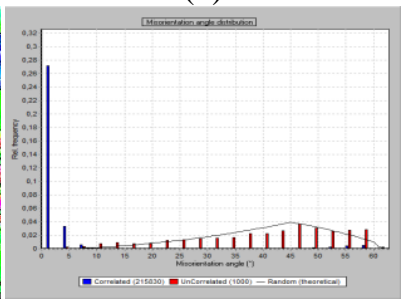

(d)
Fig. 6. IPF coloring map relative to ND and misorientation angle distribution of commercial pure $\mathrm{Cu}$ ECAP processed at $200{ }^{\circ} \mathrm{C}$ through a, b) 1-P and c, d) 4-Bc.

Fig. 7 shows the $\{100\},\{110\}$, and $\{111\}$ pole figures for the $\mathrm{AA}$ and ECAPed $\mathrm{Cu}$ samples. The texture transformed from strong to shear post-ECAP processing through 1-P. The new texture had an intensity of 4 times random. After the $4-\mathrm{Bc}$ processing at $\mathrm{RT}$, the texture again becomes identical to the simple shear texture of roughly 7 times, whereas $4-\mathrm{Bc}$ processing at $200{ }^{\circ} \mathrm{C}$ revealed displayed a texture with an intensity of 4 times random.

\section{Mechanical properties}

\section{Tensile properties}

Fig. 8 depicts the engineering stress-strain $(\sigma-\varepsilon)$ curves before and after ECAP for the commercial pure $\mathrm{Cu}$ processed through $1-\mathrm{p}$, and $4-\mathrm{Bc}$ at $\mathrm{RT}$ and $200{ }^{\circ} \mathrm{C}$. In addition, Table 2 lists the yield strength $\left(\mathrm{YS}=\sigma_{0.2}\right)$, ultimate tensile strength (UTS), and elongation to failure (EL) achieved through ECAP processing of commercial purity $\mathrm{Cu}$ as a function of the number of passes. The AA samples exhibits the highest EL and the lowest values of UTS and YS.
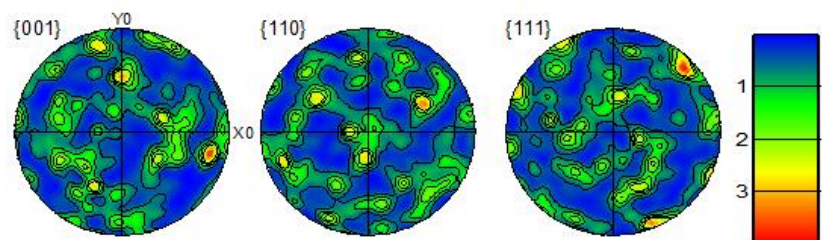

(a)
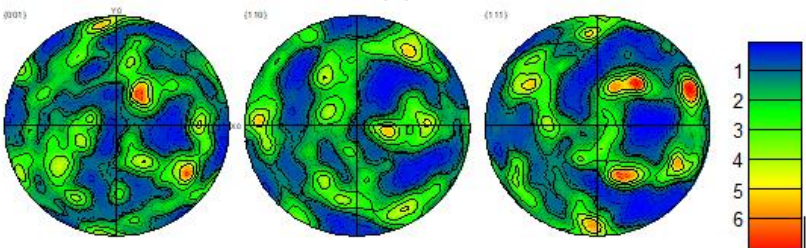

(b)
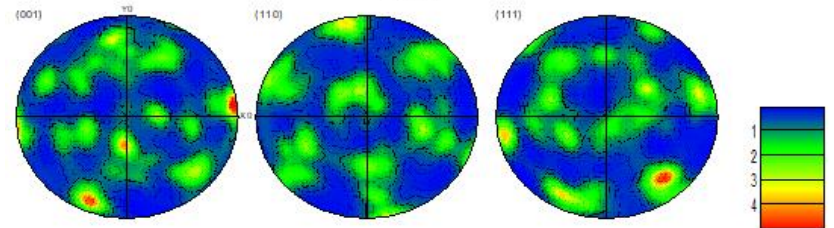

(c)
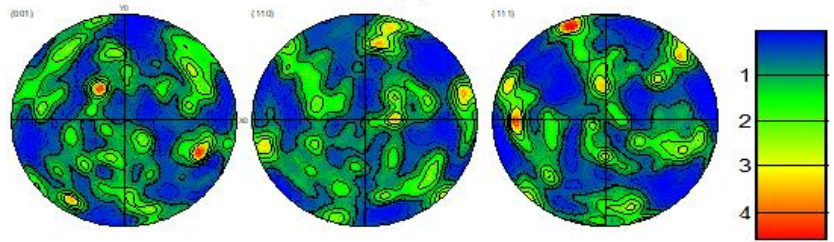

(d)
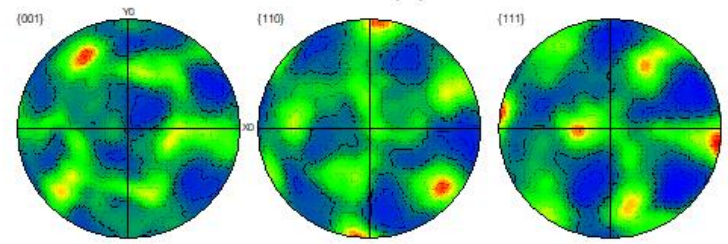

(e)

Fig. 7. $\{001\},\{110\}$ and $\{111\}$ pole figures of (a) AA, (b, d) 1-P, and (c, e) $4-\mathrm{Bc}$ pure $\mathrm{Cu}$ processed at $(\mathrm{b}, \mathrm{c}) \mathrm{RT}$, and $(\mathrm{d}, \mathrm{e}) 200^{\circ} \mathrm{C}$.

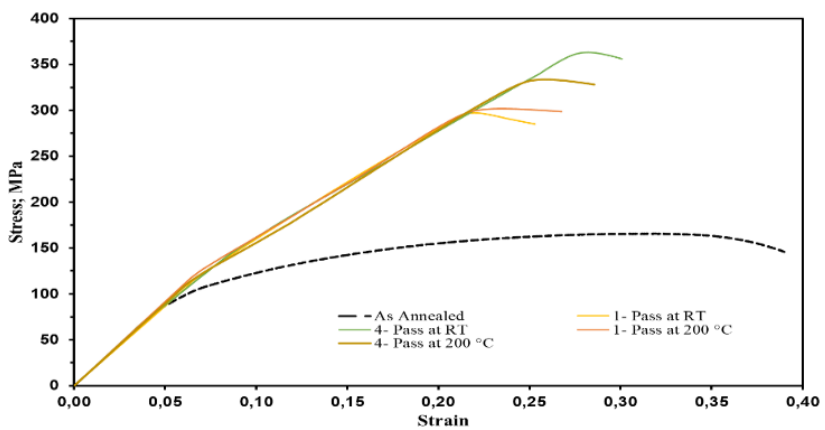

Fig. 8. Effect of ECAP processing temperature on the mechanical properties of commercial purity $\mathrm{Cu}$ as a function of increasing ECAP passes. 


\section{Advanced Materials Letters https://aml.iaamonline.org}

Table 2. Mechanical properties of commercial pure Cu processed via ECAP.

\begin{tabular}{lccccccc}
\hline $\begin{array}{l}\text { Processing } \\
\text { Condition }\end{array}$ & $\begin{array}{c}\text { Processing } \\
\text { Temperature }\end{array}$ & \multicolumn{2}{c}{ Hv-Value } & \multirow{2}{\text{YS}}{$\begin{array}{c}\text { UTS } \\
\text { TPa }\end{array}$} & $\begin{array}{c}\text { Elongation } \\
\text { MPa }\end{array}$ & $\begin{array}{c}\text { Impact } \\
\text { Energy j }\end{array}$ \\
\cline { 3 - 4 } & Center & Periphery & & & \\
\hline As-annealed & - & $55 \pm 2$ & $55 \pm 2$ & 122 & 170 & 41.5 & $63 \pm 2$ \\
1-pass & & $108 \pm 2$ & $126 \pm 2$ & 280 & 299.5 & 25.3 & $55 \pm 2$ \\
4-Bc & RT & $127 \pm 2$ & $158 \pm 3$ & 272 & 381 & 30 & $55 \pm 2$ \\
1-pass & $200^{\circ} \mathrm{C}$ & $102 \pm 1$ & $116 \pm 3$ & 292 & 302 & 26.8 & $57 \pm 2$ \\
4-Bc & & $113 \pm 2$ & $128 \pm 1$ & 292 & 330 & 28.5 & $57 \pm 2$ \\
\hline
\end{tabular}

The AA samples exhibits the highest EL and the lowest values of UTS and YS. The displayed results show a consistent increase in both the YS and UTS compared to the as-annealed billets. The uniform elongation before necking occurrence exhibits significantly decreased after processing by ECAP. Accordingly, the YS and UTS increases the sacrifice of the ductility has been induced. This is in line with the grain size refinement and the relative increase in HAGBs [35-36] with an increasing number of deformation passes. Moreover, Fig. 8 shows the YS, UTS, and EL variation of as a function of increasing the ECAP passes compared to the AA billets. It is suggested that strain hardening is the dominant strengthening mechanism and it is dependent on the amount of strain accumulation. This is evident by the recorded increase in Hv, YS and UTS values post ECAP processing. As shown in Table 2 and Fig. 8, significant improvement in the YS and UTS were observed after processing via 1-P at RT, gradual increase occurred for ensuing passes which is in a good agreement with earlier study [37]. A dramatic increase in the YS (129.5\%) and UTS $(76 \%)$ were recorded after processing through 1-P, coupled with $39 \%$ reduction in EL in comparison with AA samples. On the other hand, a gradual decrease in the incremental rate of strengthening occurred as a function of increasing number of passes. Cumulative straining up to 4$\mathrm{Bc}$ at RT resulted in an insignificant enhancement in the tensile properties, which was associated with an insignificant improvement in EL. Furthermore, compared to the AA, it is evident that processing 4-Bc through ECAP resulted in an approximate $123 \%$ increase in the YS and a $124 \%$ increase in the UTS coupled with $25 \%$ reduction in the ductility. These finding were in a good agreement with a previous study [38-40].

To explore the effect of the processing temperature on the mechanical properties of $\mathrm{Cu}$ billets, Fig. 8 shows the results of the tensile test for $\mathrm{Cu}$ after different passes of ECAP at $200{ }^{\circ} \mathrm{C}$. Comparing the results of UTS for ECAPed samples at RT and at $200{ }^{\circ} \mathrm{C}$ shows that the UTS decreases by about $13.5 \%$ in the commercially pure $\mathrm{Cu}$ samples after processing through $4-\mathrm{Bc}$ at $200^{\circ} \mathrm{C}$ compared to the processed at RT counterpart. However, no marked change in UTS was observed for the 1-P condition of ECAP between the worm processed and RT processed samples. In addition, processing through $1-\mathrm{P}$ at $200{ }^{\circ} \mathrm{C}$ revealed insignificant enhancement in the YS and ductility compared to RT counterparts where $4 \%$, and $6 \%$ improvement were recorded in the YS, and ductility, respectively. The same trend was recorded for the tensile properties of the $4-\mathrm{Bc}$ samples processed at $200{ }^{\circ} \mathrm{C}$. Accordingly, 4-Bc showed $7.3 \%$ increase in the YS whereas the EL was reduced by $5 \%$ in comparison with the RT processed counterparts. It should also be noted that there is no difference between YS recorded for 1-P and 4$\mathrm{Bc}$ conditions processed at $200{ }^{\circ} \mathrm{C}$. These results are consistent with the outcomes of a recent study $[\mathbf{3 5}, \mathbf{4 1}]$. These findings confirm that the warm processing conditions still favor the material strength increase until the first pass [32]. On the other hand, the subsequent decrease of strength in further worm ECAP passes can be explained by the occurrence of dynamic recovery and discontinuous dynamic recrystallization, which leads to the elimination of dislocations [36].

\section{Microhardness variation}

The hardness contour maps of the ECAPed $\mathrm{Cu}$ samples along the longitudinal cross-section (LS) of the $\mathrm{Cu}$ extrudate is shown in Fig. 9 after processing through 1-pass (1-P), and 4-passess of route $\mathrm{Bc}(4-\mathrm{Bc})$ at $\mathrm{RT}$ and $200^{\circ} \mathrm{C}$. The hardness contours of the AA samples were not displayed because they were essentially homogeneous across each sample with an average of $\mathrm{Hv} \sim 55$. A similar plots presented in Fig. 9 across the transverse cross-section (TS) which reveal that the strain hardening was the highest at the corner and peripheral regions and decreased towards the central regions (a)

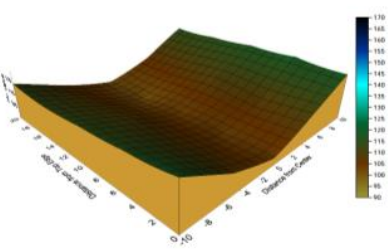

(c)

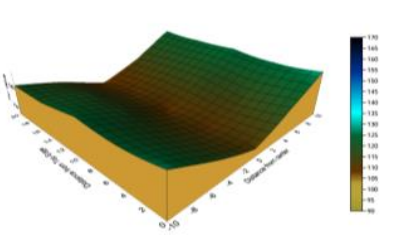

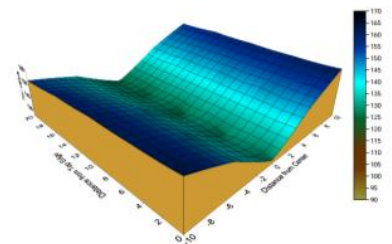

(b)

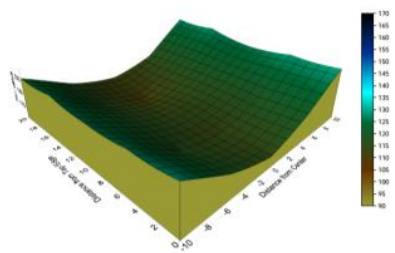

(d)
Fig. 9. Color-coded contour for the microhardness values recorded on the longitudinal planes of the $\mathrm{Cu}$ samples processed via ECAP processing after (a, c) 1-p, (b, d) 4-Bc at (a, (a, b) RT, and (c, d) $200{ }^{\circ} \mathrm{C}$.

Higher measured $\mathrm{Hv}$ values appeared in the top boundaries of the longitudinal sections of the samples, decreasing as we took measurements from farther areas till the bottom, as shown in Fig. 9. The samples which were processed through the 1-P route revealed topographicalbased variation in their microhardness values, as they had values of 126 at the top boundary, these values kept decreasing until they reached 108 at the bottom center of the sample. It was found that the $\mathrm{Hv}$ values increased significantly when the samples were further processed 


\section{Advanced Materials Letters https://aml.iaamonline.org}

through the $4-\mathrm{Bc}$ route. The samples processed via route 4-Bc had $\mathrm{Hv}$ values of up to 158 near the sample's top boundaries while the center of the samples had values of about 127, with both areas having higher $\mathrm{Hv}$ values compared to that of 1-P billets, as shown in (Fig. 9(b)). It can be understood that, according to figure $7 \mathrm{c}$, the warm processing of the billets led to the enhancement of hardness homogeneity, which then contributed to the even distribution of strain. Samples that ECAPed through route $1-\mathrm{P}$ at $200{ }^{\circ} \mathrm{C}$ had $22 \%$ higher hardness homogeneity between their centers and peripheries compared to the samples processed at RT. ECAPing the billets using the $4-\mathrm{Bc}$ route yielded even higher hardness homogeneity between the center and peripheries: up to $50 \%$ compared to the RT samples.

Due to processing at room temperature, the sample had a higher value of imposed strain. The excessive strain resulted in the rise of hardness values accompanied by a modest increase in heterogeneity. $\mathrm{Cu}$ Billets were ECAPed through the $1-\mathrm{P}$ route at $200{ }^{\circ} \mathrm{C}$, and microhardness values were measured. As illustrated in Fig. 9(c), and Table 2, it was found that the uniformity of the hardness values increased from across the center to the boundaries with values ranging from $(\sim 102 \mathrm{Hv})$ to $(\sim 116 \mathrm{Hv})$, respectively. Meanwhile, conducting multiple passes on $\mathrm{Cu}$ billets ECAPed through the 4-Bc route resulted in hardness values of $(\sim 128 \mathrm{Hv})$ near the boundaries, which is a modest increase from the $(\sim 113 \mathrm{Hv})$ values found near the central regions, shown in Fig. 9(c), Fig. 9(d).

The analysis conducted on the effects the ECAP process had on the microhardness values across the transverse section of the $\mathrm{Cu}$ sample produced many results. Firstly, ECAPing the sample through the 1-P route yielded $96 \%$ and $125 \%$ increases in the $\mathrm{Hv}$ values at the central regions and boundaries, respectively, compared to the AA condition, as shown in Fig. 10. We can conclude from these divergent increases in $\mathrm{Hv}$-values that they are hugely inhomogeneous across the TS of the rod (Fig 10(a)). Secondly, when the samples were ECAPed using the 4-Bc route, it was found that the $\mathrm{Hv}$ values across the $\mathrm{Cu}$ sample's central region and boundaries had increases in the range of $16.6 \%$ and $29 \%$, respectively, compared to the 1 $\mathrm{P}$ condition. The noticeable disparity found between the microhardness values of the boundaries and the center is a result of the friction between the rod and ECAP die walls. This deviation in microhardness distribution could be observed in the TS of the ECAPed samples processed through 1-P (shown in Fig. 10(c)) or 4-Bc (shown Fig. 10(d)). Thirdly, the Hv- values of the ECAPed samples at $200{ }^{\circ} \mathrm{C}$ were considerably lower than those of the samples processed at RT. This difference is ascribed to the increase in grain size and the decrease in the HAGBs that accompanies warm processing due to the lower imposed strain [33]. The mechanical properties of AA pure commercial $\mathrm{Cu}$ are listed alongside those of the samples processed via ECAP in Table 2. Furthermore, Table 2 shows the average $\mathrm{Hv}$-values of $\mathrm{Cu}$, measured at the center, and the boundaries of the AA billets and the samples processed by ECAP through 1-P, and 4-Bc at RT and $200{ }^{\circ} \mathrm{C}$.

\section{Impact energy}

Table 2 summarizes the absorbed impact energy for the commercial pure $\mathrm{Cu}$ before and after ECAP processing. The AA sample absorbed $63 \mathrm{j}$ before fracture, processing through 1-P at room temperature resulted in decreasing the impact energy by $12.6 \%$ compared with the AA sample which can be attributed to the ultrafine structure resulted from ECAP processing. Further straining via $4-\mathrm{Bc}$ at RT has no effect on the impact energy as shown in Table 2. Processing via $1-\mathrm{P}$ at $200{ }^{\circ} \mathrm{C}$ revealed an enhancement in the impact energy by $3.6 \%$ compared to RT processed counterparts which can be attributed to the strain softening resulting from worm processing which may dominates the strain hardening effect. Accordingly, it is worth to mentioning here that similar to RT processing, increasing the imposed strain up to $4-\mathrm{Bc}$ at $200{ }^{\circ} \mathrm{C}$ showed no effect on the absorbed impact energy.

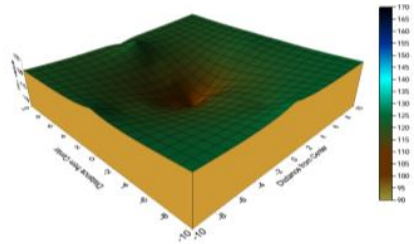

(a)

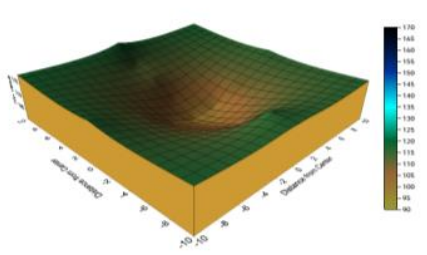

(c)

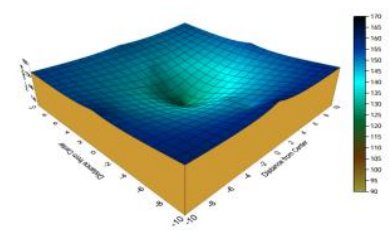

(b)

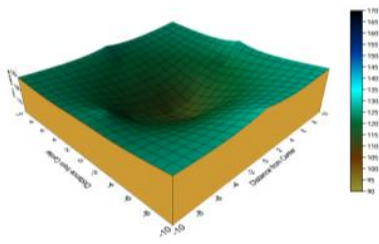

(d)
Fig. 10. Color-coded contour for the microhardness values recorded on the transverse planes of the $\mathrm{Cu}$ samples processed via ECAP processing after (a, c) 1-p, (b, d) 4-Bc at (a, (a, b) RT, and (c, d) $200^{\circ} \mathrm{C}$.

\section{Conclusions}

This study aimed to investigate the effect of the processing temperature of ECAP on the microstructure, texture evolution, micro-hardness, tensile properties and impact energy of commercial-grade pure copper. From the outcomes of the study, the following conclusions can be drawn.

1. After 4 passes, the average grain size recorded was 3.5675 and $2.2966 \mu \mathrm{m}$, obtained at room temperature and $200{ }^{\circ} \mathrm{C}$, respectively.

2. 4-P processing at RT yielded simple shear texture of roughly 7 times random, whereas $4-\mathrm{Bc}$ processing at $200{ }^{\circ} \mathrm{C}$ yielded texture with an intensity of 4 times random. 


\section{Advanced Materials Letters https://aml.iaamonline.org}

3. Increasing the deformation by processing up to 4-P resulted in increasing the strength of the ECAPed samples up to $381 \mathrm{MPa}$ and $330 \mathrm{MPa}$ for the samples processed at room temperature and $200{ }^{\circ} \mathrm{C}$, respectively.

4. The increase in the sample strength of the 4-P samples was coupled with a decrease in the ductility by $27.7 \%$, and $31.3 \%$ compared to their as-annealed counterparts.

5. Processing through 4-P revealed an increase in Vickers' micro-hardness values of the ECAPed samples by $187 \%$, and $132 \%$ at the peripheral areas at room temperature and $250{ }^{\circ} \mathrm{C}$, respectively, compared to the as-annealed samples.

6. The experimental results showed that the number of ECAP passes has insignificant effect on the impact energy.

\section{Keywords}

Severe plastic deformation, equal channel angular pressing, ultra-fine grained structure, EBSD.

\section{Received: 21 December 2020}

Revised: 5 March 2021

Accepted: 27 March 2021

\section{References}

1. Higuera-Cobos, O. F.; Cabrera, J. M.; Materials Science and Engineering: A, 2013, 571, 103.

2. Galsin, J. S.; Impurity scattering in metallic alloys. Springer Science \& Business Media, 2002.

3. Hummel, R. E.; Electronic properties of materials. Springer Science \& Business Media, 2011.

4. Han, S. Z.; Goto, M.; Lim, C.; Kim, C. J.; Kim, S.; Journal of Alloys and Compounds, 2007, 434, 304.

5. Salimyanfard, F.; Toroghinejad, M. R.; Ashrafizadeh, F.; Jafari, M.; Materials Science and Engineering: A, 2011, 528, 5348.

6. Valiev, R. Z.; Langdon, T. G.; Progress in Materials Science, 2006, 51, 881.

7. Fouad, D.M.; Moataz, A.; El-Garaihy, W.H.; Salem, H.G.; Materials Science \& Engineering A, 2019, 764, 138216

8. Fouad, D.M.; El-Garaihy, W.H.; Ahmed, M.M.Z.; El-Sayed Seleman, M.M.; Salem, H.G.; Materials Science \& Engineering A, 2018, 737, 166.

9. El-Garaihy, W.H.; Fouad, D.M.; Salem, H.G.; Metallurgical \& Materials Transaction A, 2018, 49, 2854

10. Fouad, D.M.; Moataz, A.; El-Garaihy, W.H.; Salem, H.G.; "Multiobjective Optimization of Multi-Channel Spiral Twist Extrusion Process Using a Response Surface Approach and Finite Element Analysis", Materials Science \& Technology Conference \& Exhibition Proceeding (MS \&T 2018), Columbus, Ohio, USA, October 14-18, 2018, pp: 1470-1477.

11. El-Garaihy, W.H.; El-sayed M. A. Rassoul, Ayman M. Alaskari, A.I. Alateyah, and Samy E. Oraby, SAE International Journal of Materials and Manufacturing, 2018, 11, 1 .

12. W.H. El-Garaihy, El-Sayed M.A. Rassoul, and H.G. Salem, Materials Science Forum, 2014, 783, 2623.

13. Salem, H.G.1 El-Garaihy, W.H.; El-Sayed M.A. Rassoul, "Influence of High-Pressure Torsion on the Consolidation Behavior and Mechanical Properties of AA6061-SiCp Composites Powders", Supplemented Proceeding: Volume 1, Materials Processing and Interfaces, TMS (The Minerals, Metals \& Materials Society), March (2012), 553-560

14. Lugo, N.; Llorca, N.; Cabrera, J. M.; Horita, Z.; Materials Science and Engineering: A, 2008, 477, 366.

15. Habibi, A.; Ketabchi, M.; Eskandarzadeh, M.; Journal of Materials Processing Technology, 2011, 211, 1085.
16. Molodova, X.; Gottstein, G.; Winning, M.; Hellmig, R. J.; Materials Science and Engineering: A, 2007, 460, 204.

17. El-Danaf, E. A.; Soliman, M. S.; Almajid, A. A.; El-Rayes, M. M.; Materials Science and Engineering: A, 2007, 458, 226.

18. Alateyah, A.I.; Aljohani, T.A.; Alawad, M.O.; El-Hafez, H.A.; Almutairi, A.N.; Alharbi, E.S.; Alhamada, R.; El-Garaihy, B.W.; El-Garaihy. W.H.; Metals, 2021, 11, 1.

19. Alateyah, A.I.; Alharbi, Mohammed; Abd El-Hafez, H.; El-Garaihy, W.H.; SAE Int. J. Mater. Manuf., 2021, 14, 1.

20. Almenaif, O.; Alhumaydan, Y.; Alnafisah, M.; Aldhalaan, M.; Alateyah, A.I.; El-Garaihy, W.H.; American Journal of Engineering and Applied Sciences, 2020, 13, 296.

21. Valiev, R. Z.; Islamgaliev, R. K.; Alexandrov, I. V.; Progress in Materials Science, 2000, 45, 103

22. Lugo, N.; Llorca, N.; Sunol, J.; Cabrera, J.; Journal of Materials Science, 2010, 45, 2264.

23. Zhao, Y. H.; Liao, X. Z.; Jin, Z.; Valiev, R. Z.; Zhu, Y. T.; Acta Materialia, 2004, 52, 4589 .

24. Srinivasarao, B.; Oh-Ishi, K.; Ohkubo, T.; Hono, K.; Acta Materialia, 2009, 57, 3277.

25. Valiev, R. Z.; Krasilnikov, N.; Tsenev, N.; Materials Science and Engineering: A, 1991, 137, 35

26. Iwahashi, Y.; Horita, Z.; Nemoto, M.; Langdon, T. G.; Acto Materialia, 1998, 46, 3317

27. El-Garaihy, W.H.; Adv. Mater. Lett., 2020, 11, 1

28. Liu, H.; Sun, C.; Wang, C.; Li, Y.; Bai, J.; Xue, F.; Ma, A.; Jiang, J.; Journal of Materials Science \& Technology, 2020, 59, 61.

29. He, H.; Huan, L.; Ce, W.; Jiapeng, S.; Jing, B.; Feng, X.; Jinghua, J.; Ma, A.; Journal of Magnesium and Alloys, 2019, 7, 617

30. Huang, H.; Liu, H.; Wang, Li-Sha; Yu-Hua Li; Solomon-Oshioke Agbedor, Bai, J.; Xue, F.; Jiang, Jing-Hua; Acta Metallurgica Sinica 2020, 33, 1191

31. Shaeri, M.; Karimi Taheri, K.; Karimi Taheri, A.; Shaeri, M.H. Journal of Materials Engineering and Performance, 2019, 28, 5207.

32. Higuera-Cobos, O. F.; Cabrera, J.; Materials Science and Engineering: A, 2013, 571, 103.

33. Humphreys, F. J.; Hatherly, M.; Recrystallization and Related Annealing Phenomena. Elsevier, 2012

34. Zhu, C. et al., Materials \& Design, 2013, 52, 23

35. Shaeri, M.H.; Shaeri, M.; Ebrahimi, M.; Salehi, M.T.; Seyyedein, S.H.; Progress in Natural Science: Materials International, 2016 26,182 .

36. Khelfa, T.; Muñoz-Bolaños, J. A.; Li, F.; Cabrera-Marrero, J. M.; Khitouni, M.; Metals and Materials International, 2020, 26, 1247.

37. Tong, Y.X.; Wang, Y.; Qian, Z.M.; Zhang, D.T.; Li, L.; Zheng, Y.F. Acta Metallurgica Sinica, 2018, 31, 1084

38. Saleh, B.; Jiang, J.; Xu, Q.; Fathi, R.; Ma, A.; Li, Y.; Wang, L.; Metals and Materials International, 2020, 1.

39. Yuana, T.; Jianga, J.; Ma, A.; Wu, Y.; Yuan, Y.; Li, C.; Materials Characterization, 2019, 151,530.

40. Darban, H.; Mohammadi, B.; Djavanroodi, F.; Engineering Failure Analysis, 2016, 65, 1.

41. Safari, M.; Joudaki, J.; "Effect of Temperature on Strength and Hardness in Multi-pass Equal Channel Angular Pressing (ECAP) of Aluminum Alloys”, Trans Indian Inst Met, 2020, 73, pp.619-627. 